\title{
Three species of Hitobia Kamura, 1992 (Araneae, Gnaphosidae) from south-west China
}

\author{
Cheng Wang', Xian-Jin Peng' \\ I College of Life Sciences, Hunan Normal University, Changsha, Hunan 410081, China \\ Corresponding author: Xian-Jin Peng (xjpeng@126.com)
}

Academic editor: Shuqiang Li | Received 8 August 2014 | Accepted 12 November 2014 | Published 16 December 2014

http://zoobank.org/A0CD9D06-38D9-4560-8079-FCDD90138325

Citation: Wang C, Peng X-J (2014) Three species of Hitobia Kamura, 1992 (Araneae, Gnaphosidae) from south-west China. ZooKeys 464: 25-34. doi: 10.3897/zookeys.464.8403

\begin{abstract}
Two new species and one new record of the Hitobia are described from Gaoligong Mountains, Yunnan Province, China: Hitobia tengchong sp. n. (male), Hitobia hirtella sp. n. (male) and Hitobia makotoi Kamura, 2011. Distributional data and illustrations of body and copulatory organs are provided. The differences between the new species and their related species are discussed.
\end{abstract}

\section{Keywords}

Ground spider, south-east Asia

\section{Introduction}

The genus Hitobia was established by Kamura 1992 with the type species Micaria unifascigera Bösenberg \& Strand, 1906. A total of 14 species have been reported from south-east Asia only (Platnick 2014). Subsequent papers about this genus were published by scholars from both Chinese and overseas such as Yin et al. (1996), Deeleman-Reinhold (2001), Zhang et al. (2009), Kamura (2011) and so on. Song et al. (2004) and Yin et al. (2012) made detailed studies on Chinese species of Hitobia and described 5 new species. Kamura (1992) transferred unifascigera from Poecilochroa and asiatica from Berlandina to this genus from Japan. Deeleman-Reinhold (2011) transferred tenuicincta from Ladissa to this genus from Vietnam. To date, all species of this genus (Platnick 2014) are known in China except for H. makotoi Kamura, 2011 
occurring in Japan, H. tenuicincta (Simon, 1909) from Vietnam and H. yaginumai Deeleman-Reinhold, 2001 from Thailand. Hitobia is similar to Litopyllus Chamberlin, 1922 in the condition of female median spinnerets and male palpal structure, but can be separated from the latter by the slightly recurved posterior eye row, instead of being procurved in Litopyllus (Kamura, 1992).

While examining the specimens collected from the Gaoligong Mountains (Yunnan province, south-west China) by the Sino-American Expeditions (1998-2008), one female specimen was identified to be $H$. makotoi, two male specimens were identified to be the members of Hitobia, but differ from any other males of the genus. Because of the habits of ground spider and their similar appearance, it is not easy to match male to female in each species, and many species were recorded only with single male or female in a same genus of Gnaphosidae (e. g. Micaria logunovi Zhang, Song \& Zhu, 2001 based on only one male specimen and Micaria marusiki Zhang, Song \& Zhu, 2001 based on 2 female specimens). So, we described the two male specimens as two new species. Goal of this paper is to provide the distributional data, illustrations of body and copulatory organs, and the differences between the new species and their related species.

\section{Material and methods}

All specimens were kept in 75\% ethanol, examined, measured and drawn with an Olympus SZX16 stereomicroscope and an Olympus BX53 compound microscope. Photos were taken with a digital camera Canon PowerShot G12 mounted on an Olympus SZX16 and compound focus images were generated using Helicon Focus software (3.10 Free).

All measurements were given in millimeters. Leg measurements are giving as: total length (femur, patella + tibia, metatarsus, tarsus). The abbreviations used in text including: AER anterior eye row; ALE anterior lateral eyes; AME anterior median eyes; MOA median ocular area; PER posterior eye row; PLE posterior lateral eyes; PME posterior median eyes. Specimens are deposited in College of Life Sciences, Hunan Normal University.

\section{Taxonomy}

Hitobia Kamura, 1992

Hitobia tengchong sp. $\mathrm{n}$. http://zoobank.org/A2EE881F-D6ED-4EA4-8C53-5512D8BC3B00 Figs $1-8$

Type material. Holotype: $\widehat{\partial}$, China, Yunnan: Tengchong County, Jietou Township, 8\# boundary post of Yakou $\left(25^{\circ} 80.894^{\prime} \mathrm{N}, 98^{\circ} 62.080^{\prime} \mathrm{E}, 2890 \mathrm{~m}\right), 23$ May 2006, Xingping Wang, Xianjin Peng leg. 


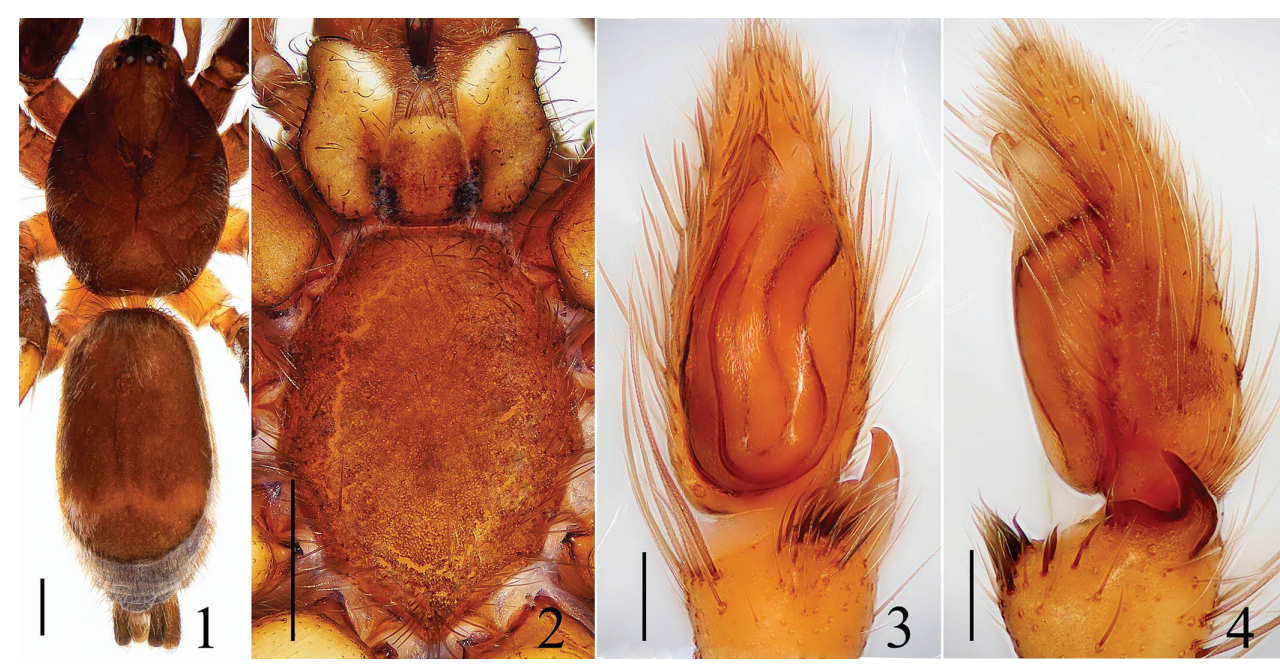

Figures I-4. Hitobia tengchong sp. n. I male body, dorsal view $\mathbf{2}$ prosoma, ventral view $\mathbf{3}$ male palp, ventral view 4 male palp, retrolateral view. Scale bars: $0.5 \mathrm{~mm}$ (I-2); $0.1 \mathrm{~mm}(\mathbf{3}-\mathbf{4})$.

Etymology. The specific name refers to the type locality; adjective.

Diagnosis. This new species is somewhat similar to $H$. yaginumai Deeleman-Reinhold, 2001 (see Deeleman-Reinhold 2001: figs 868-874), especially in opisthosoma having a large dorsal scutum, retrolateral tibial apophysis bearing a tuft of long setae on the base, male palp with a obvious conductor, but can be distinguished from the latter by: 1) embolus erect, the tip reached to the position of 11:00 o'clock approximately (Figs 3,7$)$ versus encircling along the top of bulb prolaterally, the tip reached to the position of 2:00 o'clock in $H$. yaginumai; 2 ) conductor lamellate in retrolateral view (Figs 4, 8) versus almost semicircular in H. yaginumai; 3 ) retrolateral tibial apophysis hornlike and its apex only extending to the quarter of cymbium in retrolateral view (Figs 4, 8) versus hook-like and its apex extending about to the middle part of cymbium in $H$. yaginumai; 4) abdominal dorsum only with one transverse white stripe (Fig. 1) versus with two additional short longitudinal white stripes on each side except for one transverse white stripe in $H$. yaginumai; 5) chelicerae with 3 promarginal teeth (Fig. 6) versus 2 in $H$. yaginumai.

Description. Male: Total length 5.15. Prosoma 2.29 long, 1.67 wide. Opisthosoma 2.72 long, 1.52 wide. Clypeus 0.05 high. Carapace dark brown, long oval, widest at coxae II and III, covered with some white hair. Cervical grooves, fovea and radial grooves dark brown. AER and PER both slightly recurved, wider posteriorly (Fig. 5). Eyes sizes and interdistances: AME 0.08, ALE 0.08, PME 0.07, PLE 0.09, AMEAME 0.04, AME-ALE 0.01, PME-PME 0.09, PME-PLE 0.09, ALE-PLE 0.14. MOA anterior width 0.18 , posterior width 0.22 , length 0.25 . Chelicerae brown, with 3 promarginal teeth and 1 retromarginal (Fig. 6). Endites yellowish brown, almost parallel (Fig. 2). Labium yellowish brown, longer than wide, ligulate (Fig. 2). Sternum colored as labium, covered with some dark bristles, anterior straight and posterior 

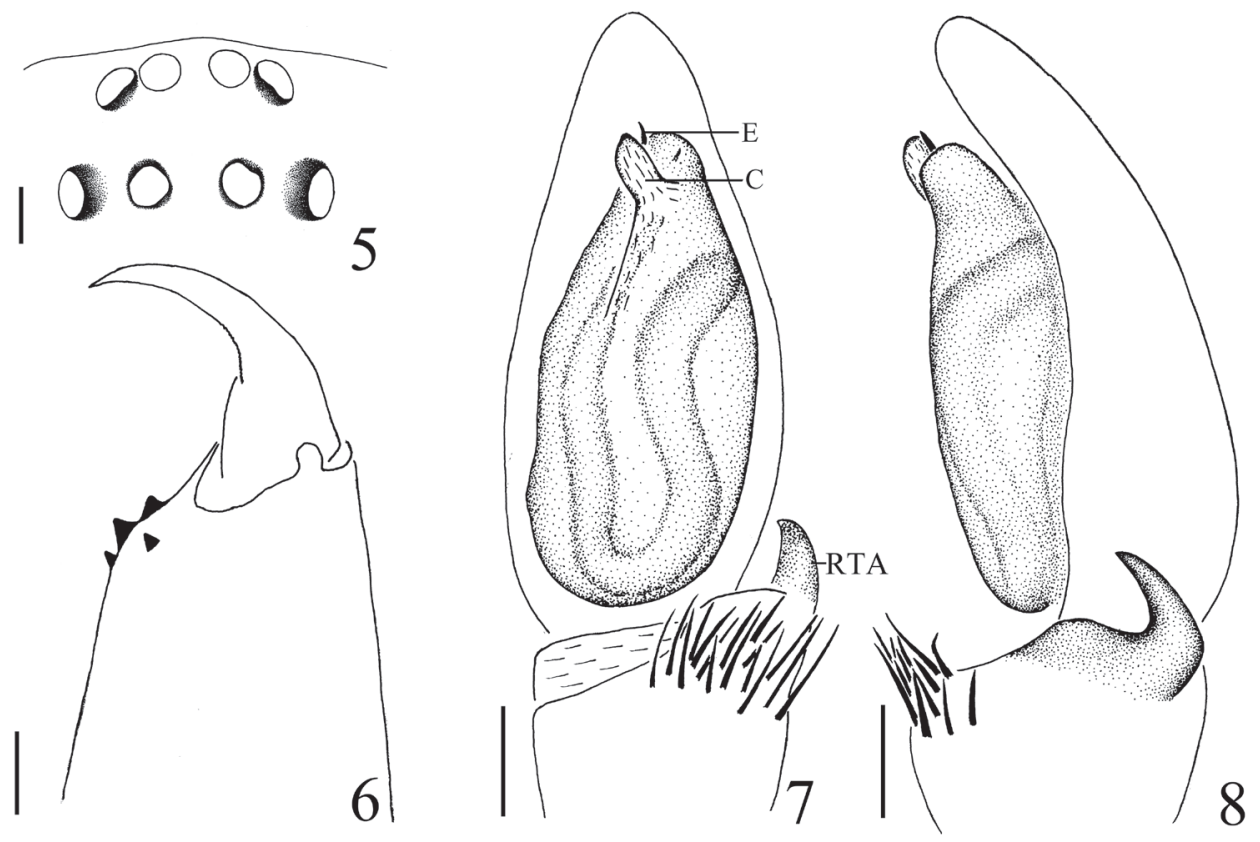

Figures 5-8. Hitobia tengchong sp. n. 5 eye area, dorsal view $\mathbf{6}$ left chelicera, posterior view $\mathbf{7}$ male palp, ventral view 8 male palp, retrolateral view. Scale bars: $0.1 \mathrm{~mm}(\mathbf{5 - 8})$. C conductor $\mathbf{E}$ embolus RTA retrolateral tibial apophysis.

subacute (Fig. 2). Legs femur, coxae I and II dark brown, others yellowish brown. Trochanters I and II without ventral notch, trochanters III and IV with a shallow ventral notch. Legs spinnation: femur: I, II, III d1-1-0, r0-0-1; IV d0-0-1; patella: I, II, III p0-1-0; IV p0-1-0; tibia: I v1-1-1; II v1-1-1; III d1-0-0, p1-0-0, v1-0-0, r1-1-1; IV d1-0-0, v1-0-1, r0-1-0; metatarsi: I v1-0-0; II v1-0-0, p1-0-0; III d1-0-0, p0-1-0, v1-0-0; IV d1-1-0, p0-1-0, r0-1-0, v1-1-0. Legs length: I 4.65 (1.31, 1.72, 1.02, 0.60), II $4.61(1.29,1.70,1.02,0.60)$, III $4.28(1.02,1.45,1.21,0.60)$, IV $5.84(1.71,2.00$, $1.53,0.60$ ). Dorsum of opisthosoma (Fig. 1) dark brown, long oval, with a large scutum about four-fifths of the whole abdominal length and one transverse white stripe posteriorly, covered with white thin hair. Venter brown.

Male palp (Figs 3-4, 7-8): tibia short, with several long prolatral macrosetae, the retrolateral apophysis hornlike and bearing a tuft of long and curved macrosetae on the base. Bulb elongated, widest at middle part. Embolus thin and short, originating from the prolateral top of bulb, erect, the tip reached to the position of 11:00 o'clock approximately in ventral view. Conductor large relatively, membranous, situated retrolaterally at embolus, lamellate in retrolateral view.

Female: Unknown.

Distribution. China (Yunnan). 


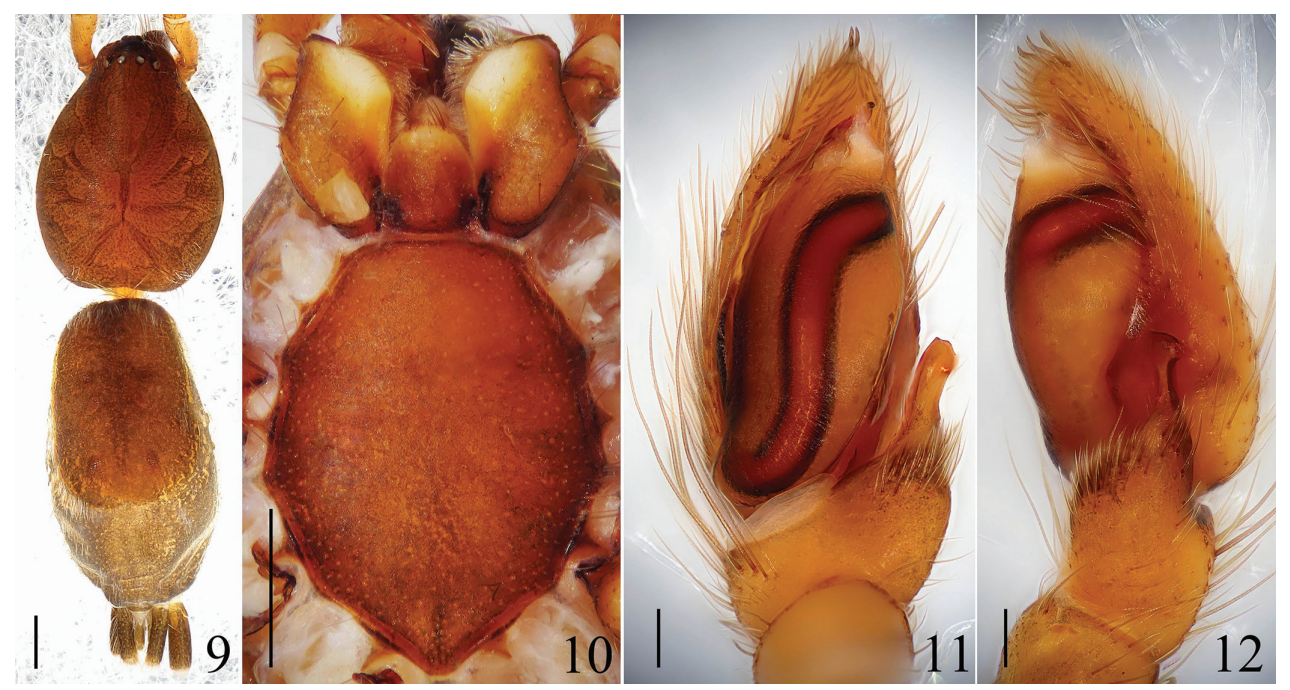

Figures 9-12. Hitobia subhirsuta sp. n. 9 male body, dorsal view $\mathbf{1 0}$ prosoma, ventral view II male palp, ventral view $\mathbf{I} 2$ male palp, retrolateral view. Scale bars: $0.5 \mathrm{~mm}(\mathbf{9}-\mathbf{I 0}) ; 0.1 \mathrm{~mm}(\mathbf{I} \mathbf{I}-\mathbf{I})$.

\section{Hitobia hirtella sp. $\mathbf{n}$.}

http://zoobank.org/67B532D8-9C8E-477A-8339-EFDDE055615C

Figs $9-16$

Type material. Holotype $\widehat{\partial}$, China, Yunnan: Nujiang Prefecture, Gongshan County, Pengdang Township, Longpo Village, 12.5 air km of Gongshan $\left(27^{\circ} 85.608^{\prime} \mathrm{N}\right.$, $\left.98^{\circ} 68.448^{\prime} \mathrm{E}, 1550 \mathrm{~m}\right), 4-7$ July 2000, Hengmei Yan leg.

Etymology. The specific name comes from the Latin hirtella (with macrosetae), referring to the three thick setae on the cymbial tip.

Diagnosis. This new species resembles H. shaohai Yin \& Bao, 2012 (see Yin et al. 2012: figs 631a-h) in having a similar size of dorsal scutum, retrolateral tibial apophysis bearing a cluster of bristles on the base, but can be separated by: 1) conductor visible in ventral view (Figs 11, 15) versus invisible in $H$. shaohai; 2 ) retrolateral tibial apophysis longer, stronger, the distal end not bifurcated (Figs 11-12, 15-16) versus with two rami in $H$. shaohai; 3) opisthosoma dorsum without obvious markings (Fig. 9) versus with one median pale transverse white stripe in $H$. shaohai; 4) chelicerae with 3 promarginal teeth (Fig. 14) versus with 2 in H. shaohai.

Description. Male: Total length 5.30. Prosoma 2.33 long, 1.75 wide. Opisthosoma 2.85 long, 1.63 wide. Clypeus 0.06 high. Carapace brown, long oval, widest at coxae II and III, covered with some white hair. Fovea, cervical grooves and radial grooves dark brown. AER and PER both slightly recurved, wider posteriorly (Fig. 13). Eyes sizes and interdistances: AME 0.08, ALE 0.10, PME 0.09, PLE 0.09, AME-AME 0.05, ALE-AME 0.01, PME-PME 0.10, PME-PLE 0.10, ALE-PLE 0.14. MOA 

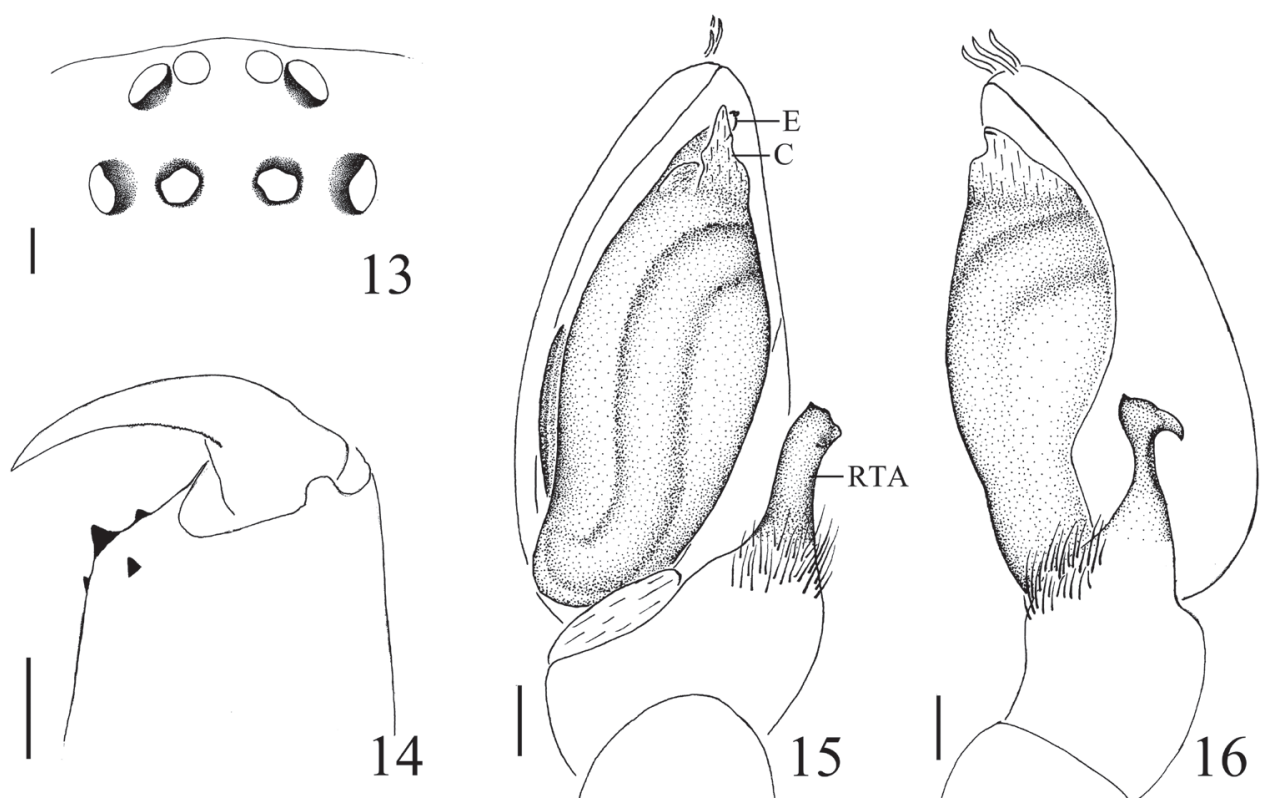

Figures 13-16. Hitobia subhirsuta sp. n. I3 eye area, dorsal view 14 left chelicera, posterior view I5 male palp, ventral view 16 male palp, retrolateral view. Scale bars: $0.1 \mathrm{~mm}$ (13-16). C conductor E embolus RTA retrolateral tibial apophysis.

anterior width 0.21 , posterior width 0.25 , length 0.29 . Chelicerae dark brown, with 3 promarginal teeth and 1 retromargianal tooth (Fig. 14). Endites yellowish brown, almost parallel (Fig. 10). Labium brown, longer than wide, ligulate (Fig. 10). Sternum brown, with some dark bristles, anterior straight and posterior subacute (Fig. 10). Legs femur, coxae I and II dark brown, others yellow. Trochanters I and II without ventral notch, trochanters III and IV with a shallow ventral notch. Leg spination: femur: I, II, III d1-1-1; IV d1-0-0; tibia: I v2-2-1; II v2-2-1; III d1-0-0, p0-1-0, v0-2-0; IVv1-2-1, r1-1-0; metatarsi: Iv0-1-0; II v1-0-0; III d0-1-0, p1-0-1, v2-0-0, r1-0-0; IV d1-0-0, p1-0-1, r0-1-0. Legs length: I 4.85 (1.50, 1.79, 0.91, 0.65), II 4.82 (1.50, 1.76, 0.91, $0.65)$, III 4.7 (1.32, 1.51, 1.22, 0.65), IV $6.11(1.75,2.00,1.71,0.65)$. Dorsum of opisthosoma (Fig. 18) brown, long oval, with three pairs of muscle impressions and a scutum about three-fifths of whole abdominal length, without obvious markings. Venter pale brown.

Male palp (Figs 11-12, 15-16): tibia short and strong, with several long prolatral macrosetae, the retrolateral apophysis long and bearing a tuft of long bristles on the swollen base. Cymbial tip with three thick setae. Embolus thin, twisted in middle part and the distal part covered by large conductor is, membranous, almost triangular in ventral view.

Female: Unknown.

Distribution. China (Yunnan). 


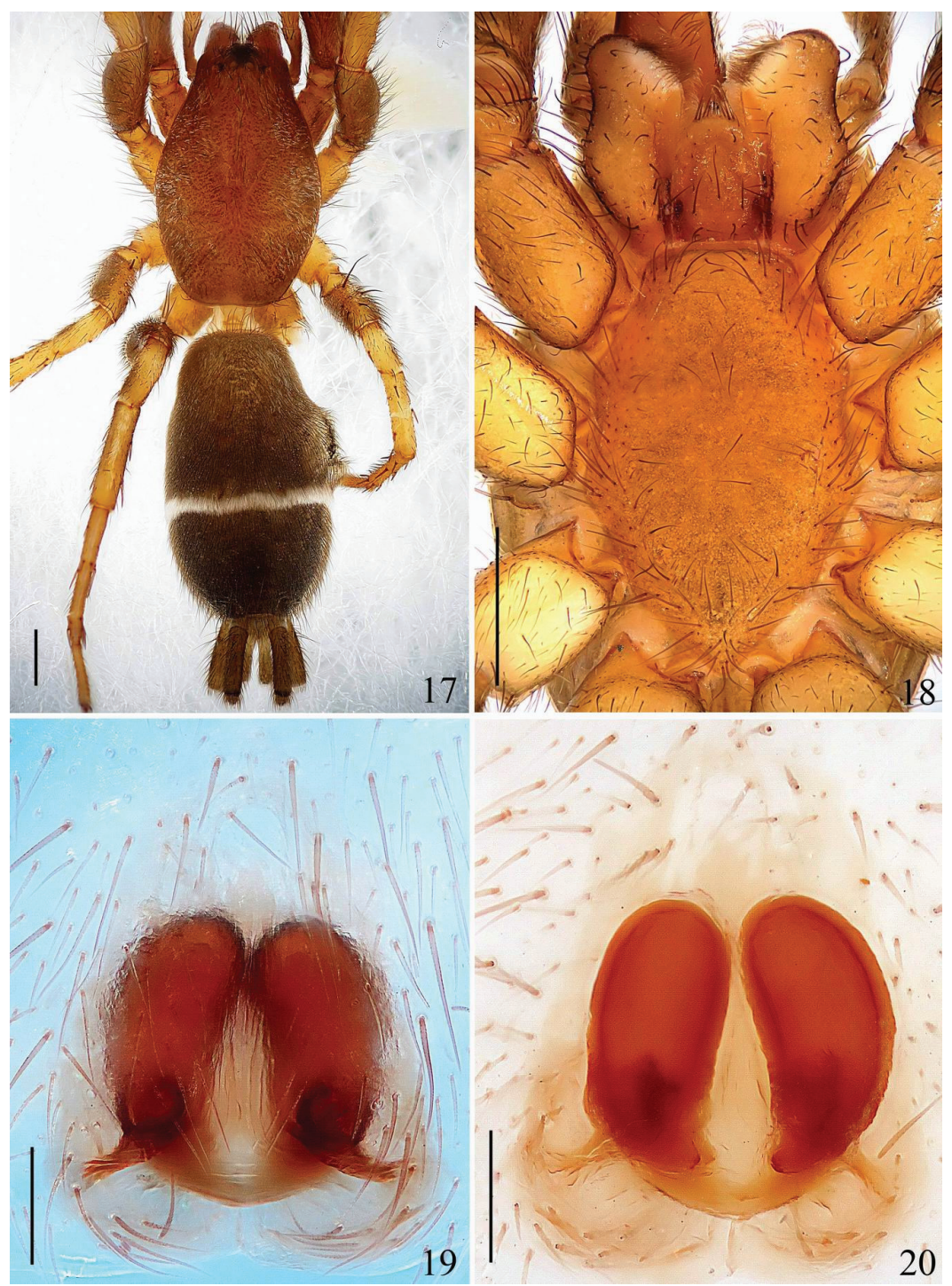

Figures 17-20. Hitobia makotoi Kamura, $2011 \mathbf{I 7}$ female body, dorsal view $\mathbf{1 8}$ prosoma, ventral view 19 epigyne, ventral view 20 vulva, dorsal view. Scale bars: 0.5 mm (17-18); $0.1 \mathrm{~mm}$ (19-20).

\section{Hitobia makotoi Kamura, 2011}

Figs $17-23$

Hitobia makotoi Kamura, 2011: 104, f. 3-7 (Df).

Material examined. 1 9 , China, Yunnan: Tengchong County, Qingshui Township, Rehai area, Liangyong Village $\left(2^{\circ} 94.919^{\prime} \mathrm{N}, 98^{\circ} 44.921^{\prime} \mathrm{E}, 1450 \mathrm{~m}\right), 1$ June 2006, D. H. Kavanaugh, R. L. Brett, Dazhi Dong leg. 

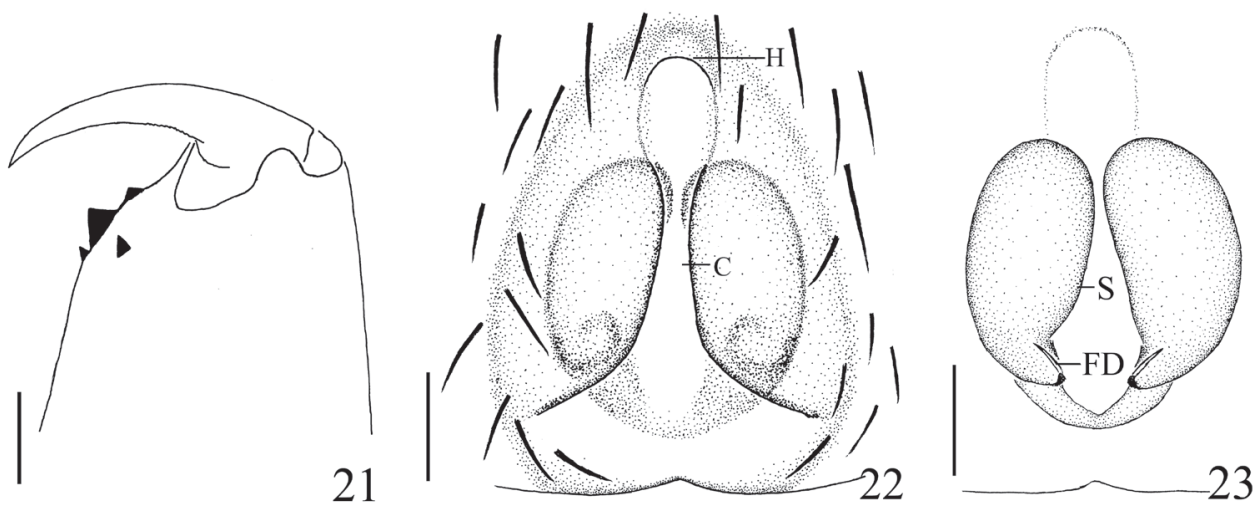

Figures 2I-23. Hitobia makotoi Kamura, 2011, 2I left chelicera, posterior view 22 epigynum, ventral view 23 vulva, dorsal view. Scale bars: $0.1 \mathrm{~mm}(\mathbf{2} \mathbf{I}-\mathbf{2 3})$. C concavity FD fertilization ducts $\mathbf{H}$ hood $\mathbf{S}$ spermathecae.

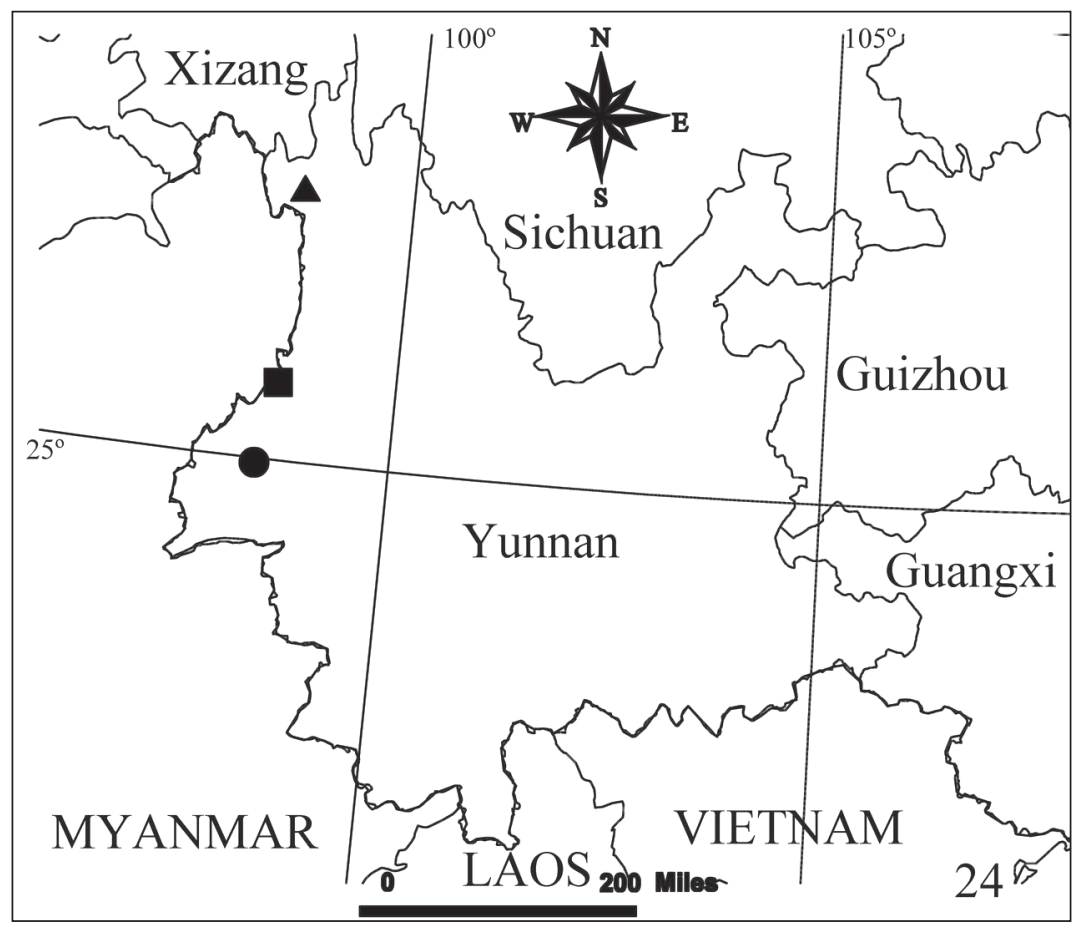

Figure 24. Distribution records of the three species of genus Hitobia from south-west China. $\mathbf{\Delta}$ H. hirtella; - H.tengchong, $\bullet$ H. makotoi.

Description. Female: Total length 5.08. Prosoma 2.28long, 1.45 wide. Opisthosoma 2.63 long, 1.47 wide. Clypeus 0.06 high. Carapace blackish brown, long oval, widest at coxae II and III, covered with some white hair. Fovea, cervical grooves indistinct. AER and PER both slightly recurved, wider posteriorly. Eyes sizes and interdistances: AME 
0.09, ALE 0.09, PME 0.07, PLE 0.08, AME-AME 0.03, AME-ALE 0.01, PME-PME 0.08, PME-PLE 0.09, ALE-PLE 0.13. MOA anterior width 0.18, posterior width 0.21 , length 0.23 . Chelicerae dark brown, with 3 promarginal teeth and 1 retromarginal (Fig. 21). Endites narrowed medianly and slightly convergent apically, almost parallel (Fig. 18). Labium yellowish brown, longer than wide, ligulate (Fig. 18). Sternum colored as labium, with some dark bristles, anterior straight and posterior subacute (Fig. 18). Legs femur, trochanters I and II, coxae I and II brown, others light yellow. Trochanters I and II without ventral notch, trochanters III and IV with a shallow ventral notch. Legs spinnation: femur: I, II v1-1-1; III d1-1-1, p0-0-1; IV d1-1-1, r0-0-1; patella: I, II, III, IV; tibia: I v1-1-1; II v1-0-0; III d1-1-0, p1-0-0, v1-2-1, r1-1-1; IV v1-0-2, r0-1-1; metatarsi: I d0-1-0; II v1-0-0; III d0-1-1, p0-1-1, v1-0-2, r1-0-1; IV d1-1-0, p0-1-0, v0-2-1, r0-0-1. Measurements of legs: I 4.36 (1.35, 1.65, 0.75, 0.61), II 4.28 (1.30, $1.62,0.75,0.61)$, III $4.21(1.15,1.31,1.00,0.75)$, IV $5.30(1.75,1.85,1.00,0.70)$. Dorsum of opisthosoma (Fig. 17) grayish brown, long oval, with three pairs of muscle impressions at central part and one narrow transverse white stripe posteriorly, covered with recumbent hair. Venter pale brown. Spinneret cylindrical, median spinneret long, with spigots on distal part, blackish brow.

Epigyne (Figs 19-20, 22-23) longer than wide, with a distinct anterior hood, and shallow longitudinal concavity in median part. Spermathecae big, elongated and the distal parts close to each other.

Male: Unknown.

Distribution. China (Yunnan), Japan (Amami-öshima Is.).

Comments. Although the spermathecae of the specimen are smaller, the distal parts close to each other (almost parallel to each other in the original description of Kamura (2011)), the following characters of the specimen are almost as same as those described in the original description: the position and form of stripes on the dorsum of opisthosoma; epigyne with a distinct anterior hood, a shallow longitudinal concavity in median part, copulatory opening indistinct; hence the specimen was identified as Hitobia makotoi Kamura, 2011.

\section{Acknowledgements}

We are grateful to Dr. Peter Fritsch (California Academy of Sciences) and Prof. Heng Li (Kunming Institute of Botany, Chinese Academy of Science Kunming Institute of Botany, Chinese Academy of Science) for supporting the joint biodiversity survey of the Gaoligong Mountains. We thank Prof. D. H. Kavanaugh, R. L. Brett, Hengmei Yan, Xingping Wang and Mr. Dazhi Dong for collecting the specimens. Special thanks also should be given to Prof. T. Kamura for his kind help on specimens identification. This research was sponsored by the National Science Foundation of the USA through the grant "Biotic survey of the Gaoligongshan, a biodiversity hotspot in western Yunnan, China” (No. DEB-0103795). It is also partly supported by the National Natural Sciences Foundation of China (NSFC-30970327, 31272271, 31272272), 
Hunan Provincial Natural Science Foundation of China (No.11JJ1004/12JJ3028), Program for New Century Excellent Talents in University (NCET-12-0717), China Postdoctoral Science Foundation (No. 20100471221/201104506), the program of Hunan Provincial Science and Technology Plans (No. 2010RS4006) and by the Hunan Provincial Program for Development of Key Disciplines in Ecology.

\section{References}

Deeleman-Reinhold CL (2001) Forest spiders of South East Asia: with a revision of the sac and ground spiders (Araneae: Clubionidae, Corinnidae, Liocranidae, Gnaphosidae, Prodidomidae and Trochanterriidae [sic]). Brill, Leiden, 591 pp.

Kamura T (1992) Two new genera of the family Gnaphosidae (Araneae) from Japan. Acta arachnol 41: 119-132.

Kamura T (2009) Trochanteriidae, Gnaphosidae, Prodidomidae, Corinnidae. In: Ono H (Ed.) The Spiders of Japan with keys to the families and genera and illustrations of the species. Tokai University Press, Kanagawa, 482-500, 551-557.

Kamura T (2011) Two new species of the genera Drassyllus and Hitobia (Araneae: Gnaphosidae) from Amami-ôshima Island, southwest Japan [J]. Acta Arachnologica 60 (2): 103-106. doi: 10.2476/asjaa.60.103

Platnick NI (2013) The world spider catalog, version 14.5. American Museum of Natural History. http://research.amnh.org/entomology/spiders/catalog/ [accessed 31 December 2013]

Song DX, Zhu MS, Chen J (1999) The Spiders of China. Hebei Science and Technology Publishing House, Shijiazhuang, 640.

Song DX, Zhu MS, Zhang F (2004) Fauna Sinica: Arachnida: Araneae: Gnaphosidae. Science Press, Beijing, $362 \mathrm{pp}$.

Wang JL, Peng XJ (2013) Description of Leucauge tengchongensis sp. nov. and the female of Okileucauge elongatus from Yunnan, China (Araneae: Tetragnathidae). Acta Arachnol. Sin. 22: 16-23.

Yin CM, Peng XJ, Gong LS, Kim JP (1996) Description of three new species of the genus Hitobia (Araneae: Gnaphosidae) from China. Korean Arachnology 12(2): 47-54.

Yin CM, Peng XJ, Yan HM, Bao YH, Xu X, Tang G, Zhou SQ, Liu P (2012) Fauna Hunan: Araneae in Hunan, China. Hunan Science and Technology Press, Changsha, 1590 pp.

Zhang F, Zhu MS, Tso IM (2009) Three new species and two new records of Gnaphosidae (Arachnida: Araneae) from Taiwan. Journal of Hebei Normal University 29: 528-532. 